Article

\title{
The Effect of Structured Feedback on Performance: the Role of Attitude and Perceived Usefulness
}

\author{
Sarah Cheah * and Shiyu Li \\ School of Business, National University of Singapore, Singapore 119245, Singapore; obrls@nus.edu.sg \\ * Correspondence: sarahcheah@nus.edu.sg
}

Received: 31 December 2019; Accepted: 4 March 2020; Published: 9 March 2020

\begin{abstract}
In higher education, university students need to be equipped with the necessary knowledge and skills for their future workplace. Companies provide opportunities for students to participate as trainee consultants in innovation-related projects as a form of experiential learning. We designed a quasi-experimental study to investigate how supervisors' structured feedback can influence students' learning and project performance. We recruited 28 business school final year undergraduates who formed teams of four students either by themselves or with the help of the school. We randomly assigned three teams with 12 students to the treatment group and four teams of 16 students to the control group. In the treatment group, company supervisors were asked to provide structured written feedback for the treatment group using structured feedback forms, which focus students' attention on task level, process level, and self-regulation level at three project milestone stages. In the control group, students received feedback from company supervisors without any feedback form. At the end of this project, a survey was conducted to measure students' attitudes toward feedback in supporting learning and their perceived usefulness of company supervisors' feedback. The results show that company supervisors' structured feedback positively affected students' overall project performance in presentation and report, and students' positive attitudes toward feedback and perceived usefulness of company supervisor's structured feedback are positively related to students' report performance.
\end{abstract}

Keywords: structured feedback; project-based learning; project performance

\section{Introduction}

The world is presently facing environmental challenges, such as global warming, that have enormous impact on economic growth of many countries [1]. Hence, much research has been done on the concepts of sustainable development, which is defined as a reaction to concern about how the environment is affected by and in turn affecting our society [2]. According to the Brundtland Commission, sustainable development is defined as "development that meets the needs of present without compromising the ability of future generations to meet their own needs" [3] (p. 128). Education plays an important role in adapting changes toward sustainable development [4], which promotes the development of the knowledge, skills, understanding, values and actions required to create a sustainable world, to ensure environmental protection and conservation, promote social equity, and encourage economic sustainability [2] (p. 50). According to United Nations Educational, Scientific and Cultural Organization (UNESCO), education for sustainable development (ESD) adapted certain important elements, including promoting critical, innovative and reflective thinking and learning in educational programs. Hence, innovative pedagogical methods should be adopted in current education institutions to facilitate ESD and promote students' critical thinking, creativity and reflective thinking, which are essential for education on sustainability [4].

Transformative learning is one type of learning that is usually adopted for ESD, which places heavy emphasis on student's dynamic qualities or abilities to address uncertainty. This is achieved 
by critically reflecting on one's knowledge and experiences [5]. The key focus is on what students have learnt instead of what teachers or supervisors have taught [6]. In this new method, it encourages students' self-learning under teachers' supervision as it enables students to develop abilities to manage and apply the knowledge [6]. According to the experiential learning theory, learning is defined as "the process whereby knowledge is created through the transformation of experience. Knowledge results from the combination of grasping and transforming experience" [7] (p. 67). In Kolb's model, a concrete experience is necessary for reflective observation. After reflecting on it, learners can form abstract conceptualization and hence actively try out what they have learned. The main concept is experimentation and reflection, which are the key elements for ESD. In this learning method, learners are self-determinants of the learning by experimenting and reflecting.

To promote ESD based on experiential learning theory, project-based learning (PBL) is one of the most suitable experiential learning approaches, as it emphasizes that learners acquire new knowledge based on their previous knowledge and experience [8]. PBL is an inquiry-based method that focuses on learning by doing, in which learners solve problems by searching various resources in the real world within a given period of time [9]. It is a pre-professional practice that aims to link learnt knowledge with operation-specifically, joining experimental learning to real life applications [8]. PBL places heavy emphasis on learners' autonomy and initiative. Besides that, it requires students to integrate knowledge from diverse disciplines. It helps students to develop their collaborative and team spirit. Hence, it enables learners to develop skills in technical, contextual, and behavioral realms $[8,10]$, which are important for their future professional competency. In addition, PBL stimulates learners' innovative thinking, productive thought, and motivation to learn and work on problems [8].

PBL encourages learners to accomplish a task within a specific period under the guidance and support from supervisors [9]. The capstone project based on PBL is a multifaceted assignment that is designed for students who have high academic skill and is often carried out in the final year schooling [11]. The importance of PBL leads many higher educational institutions to offer internship and field service project (FSP) programs with companies for their students. FSP programs aim to help students gain practical experience by learning in a real-work environment. Several studies addressed students' FSP programs from different dimensions, including methods, effectiveness and evaluation of such programs. Some studies showed that students rate their internship experience favorably, citing factors like organizers' operational and administrative efforts in determining the success of the internship program [12].

As students work on their field service projects to complete certain projects under the guidance of a supervisor, feedback is very important for their knowledge acquisition and improvement. One earlier study addressing this topic showed that further education by assessment with feedback was of benefit to interns' performance [13]. Another study from the health sector found that interns, in general, are unable to confidently judge their own performance [14]. Some researchers focused on enhancing feedback effectiveness by giving educators some tips $[15,16]$ and strategies $[17]$ or by suggesting that delivering feedback is a supervisory skill that should be learned in special workshops [18].

Feedback plays an important role in determining students' performance and learning in unstructured learning environment such as internship and field service projects. A recent research by Al-Hattami in 2019 [19] highlighted the importance of providing constructive feedback as a crucial tool to the process of teaching and learning. Prior studies focus only on suggesting better ways to evaluate and improve teachers' feedback in traditional classroom setting with structured content [20,21], but there are limited studies that examine the relationship between company supervisors' structured feedback and undergraduates' oral and written performance when working on company projects as part of their higher education in business, and little empirical research on how students' attitudes and perceived usefulness toward feedback affect their oral and written performance. Hence, this drives our motivation to conduct this study. In this study, we aim to investigate the impact of offering structured feedback to FSP students on their performance in reports and how such feedback impact can be influenced by the perceived usefulness of the feedback and student's attitudes toward the feedback. 
The relations and interactions between these factors are discussed in this paper. The originality of our study therefore lies in our empirical experimental study of the effect of company supervisors' feedback, students' attitudes toward feedback and perceived usefulness of feedback on students' performance outside traditional classroom learning, particularly in the unstructured PBL context that has not erstwhile been empirically examined. From a theoretical perspective, this study will deepen our current understanding of the factors influencing students' performance and shed light on the potential benefits of using structured feedback in FSP programs. In practice, lecturers and supervisors of FSP programs can gain insight on how to utilize feedback in their programs and what to expect from implementing such feedback.

\section{Background and Hypotheses}

As students work on their projects under the guidance of supervisors, feedback is very important for their knowledge acquisition and improvement. Effective and useful feedback specifically relate to the task or process of learning that reduces the discrepancies between what is understood and what is meant to be understood [22]. Feedback enhances learner's performance by allowing them to detect and correct the errors in their current strategies and further elevates their perception of competency [23]. Supervisor's feedback was found to be helpful in clarifying employee's role perception and performance expectations, enabling them to modify their behavior to achieve desired performance [24].

Although feedback can improve learner's performance, the effectiveness of feedback is determined by various factors. For example, it was established that elaborated feedback does not necessarily improve learner's performance as compared to simple feedback [25]. Learner's prior knowledge and task difficulty are found to moderate the effectiveness of feedback on learning performance [26]. The method that supervisors use to reduce the discrepancy between current and target states could be effective or ineffective in influencing students' learning. To identify the factors affecting feedback effectiveness on learning performance, a model of feedback is proposed by Hattie and Timperley [22]. To close the gap between current states and desired goals, it is vital to be aware of and understand the situation and factors causing the discrepancies. Effective feedback must answer three major questions, which are where am I going (what are the goals?), how am I doing (what is the progress?), and where to next (what kind of improvement can be made to improve the progress?). While answering these questions, different levels were posited: the level of task performance, the level of process of understanding how to do a task, the metacognitive process level, and the self or personal level. Feedback has varying degrees of impact across these levels.

To answer the question of where am I going, learners and supervisors must not only set specific goals that have appropriate challenges, but also be committed to these goals. Next, to know clearly the question of how am I doing, assessments or tests can be given to help the learners to understand better. For the last question of where to next, the feedback provided can include greater challenges, higher motivation and self-regulation, deeper commitment or more strategies. These three questions are usually integrated and work together when supervisors give the feedback. The effectiveness of answering these questions depends on the level at which the feedback is given, which are task level (how well tasks are understood or performed), process level (the main process needed to understand or perform tasks), self-regulation level (self-monitoring, directing and regulating of actions), and self level (personal evaluations and affect). It is vital to make sure that feedback is delivered to students at appropriate levels using suitable methods, since it has generally been accepted that some feedback is effective while other ineffective in students' learning.

In this study, we will adopt the model of feedback proposed by Hattie and Timperly in 2007 [22] and compare its effectiveness with that of the traditional method of providing feedback. In the traditional method, supervisor's feedback is generally ad hoc in schedule and random in content exchanges with the learners. The structured model of feedback proposed by Hattie and Timperly is differentiated from the traditional method by distinguishing supervisors' feedback among various feedback levels. In the treatment group for our study, a structured feedback form was designed with 
the three levels of feedback (task, process, self-regulation) for company supervisors to provide written feedback to the students. In the control group, the company supervisors used the traditional method of providing feedback with no clear distinction among the various feedback levels. We predicted that students in the treatment group will perform better than those in the control group based on supervisors' different methods of providing feedback.

\subsection{Structured Company Supervisor's Feedback and Students' Presentation/Report Performance}

Earley showed that level of trust in the feedback source does not affect feedback effectiveness [27]. However, the specificity of given feedback was found to affect individuals' performance. Individuals who received specific feedback would outperform those who receive general feedback, and this is mediated by more detailed planning that is stimulated by specific feedback [27]. Feedback complexity will also affect its effectiveness [28]. There are different forms of feedback content based on different levels of complexity [29]. Simple feedback includes acknowledging learners whether the answer is correct, which is termed knowledge of results. Another type of simple feedback is informing learners of the correct answer, which is termed knowledge of correct response. On the other hand, elaborated feedback further offers detailed information of the correct answer on top of knowledge of results or knowledge of correct response.

According to Wang et al. 2019 [28], a detailed explanation in the provided feedback was more effective for improving learner's performance since it contains more structured and supportive information to reduce learner's cognitive load and enables the learner to integrate new information with prior knowledge. This stems from the fact that detailed feedback leads to higher germane cognitive load and learning motivation [28]. According to the cognitive load theory, a learner's cognitive resources are limited, and excess cognitive load will impair learning process [30]. Cognitive load includes (a) intrinsic cognitive load arising from complexity of learning materials, (b) extraneous cognitive load relating to the method of presenting learning information to a learner, and (c) germane cognitive load depicting the effort to transfer knowledge into long-term memory [30]. Hence, detailed feedback helps learners to reduce ineffective cognitive load and thus increase cognitive access to error correction, as well as adopt more effective learning strategies [31]. Therefore, we predicted that structured company supervisor's feedback is positively related to students' performance as it can reduce ineffective cognitive effort and increase effective cognitive effort which is related to error correction and learning.

Hypothesis 1a: Company supervisor's structured feedback is positively related to students' presentation performance.

Hypothesis 1b: Company supervisor's structured feedback is positively related to students' report performance.

\subsection{Attitudes Toward Feedback and Students' Presentation/Report Performance}

Learners' attitudes toward feedback will largely determine the effectiveness of feedback on learning performance. However, very limited studies have been conducted to examine the role of attitudes toward feedback in affecting feedback effectiveness. As Kulhavy noted in 1977, learners can feedback may not be accepted by learners who can in fact adapt or reject it [32]. Conceptual arguments have been put forth by Butler and Winne in 1995 that the feedback given is likely to be mediated by learners' thinking, knowledge and belief of the feedback to affect the effectiveness of provided feedback [33]. Carless and Boud in 2018 also postulated that learners have to recognize and appreciate the provided feedback, develop ability to make judgements, manage their emotional responses and act upon the provided feedback [34]. In 2012, Sutton described learners' abilities to read, understand and use information to improve learning strategies as feedback literacy [35]. It is apparent that learners' attitudes toward feedback will affect their learning outcome and willingness to use the feedback. 
Wang et al.'s study of Psychology undergraduates primarily made up for female studies revealed that feedback perception of structured explanation provided in the context of psychological statistics course was rated more positive by participants [28]. This suggested that learners' attitudes toward feedback depends on the complexity of feedback provided and thus affect their learning performance. Strobl's study of Applied Languages undergraduates found that a learner's attitude toward feedback derived from online learning is likely to contribute to the mismatch between achieved performance and perceived gain from learning [36]. Building on the prior works, we argue that students' attitudes toward structured feedback can also play a role in a student's performance outside classroom learning, particularly in the PBL context that has not been empirically studied.

Hypothesis 2a: Attitude toward feedback is positively related to students' presentation performance.

Hypothesis 2b: Attitude toward feedback is positively related to students' report performance.

\subsection{Usefulness of Company Supervisor's Feedback and Students' Presentation/Report Performance}

Feedback perception is defined as learner's perception of the quality of feedback and what they do with feedback [37]. Learners' perceived usefulness of feedback has been conceptually argued to play a vital role in the effectiveness of feedback, which means that how learners perceive and understand the feedback will largely affect the effectiveness of feedback. Different forms of feedback may generate different feedback perceptions which will further influence learner's learning outcome. Harks et al.'s study of ninth graders taking a mathematics test revealed that participants perceive process-oriented written feedback as more useful than grade-oriented written feedback [38]. They found that these high-school participants' higher perceived usefulness of feedback positively correlated with their interest and achievement. This is in line with Wang et al.'s findings on psychological statistics course undergraduates who perceive detailed feedback as more useful and informative than non-detailed feedback, with positive effect on their achievement [28]. We posit that learners who have higher perception of feedback usefulness are more willing to make full use of it and thus benefits their performance. Hence, we hypothesize that students' perceived usefulness of company supervisor's structured feedback is positively related to students' performance. See Figure 1 for the conceptual model of this study.

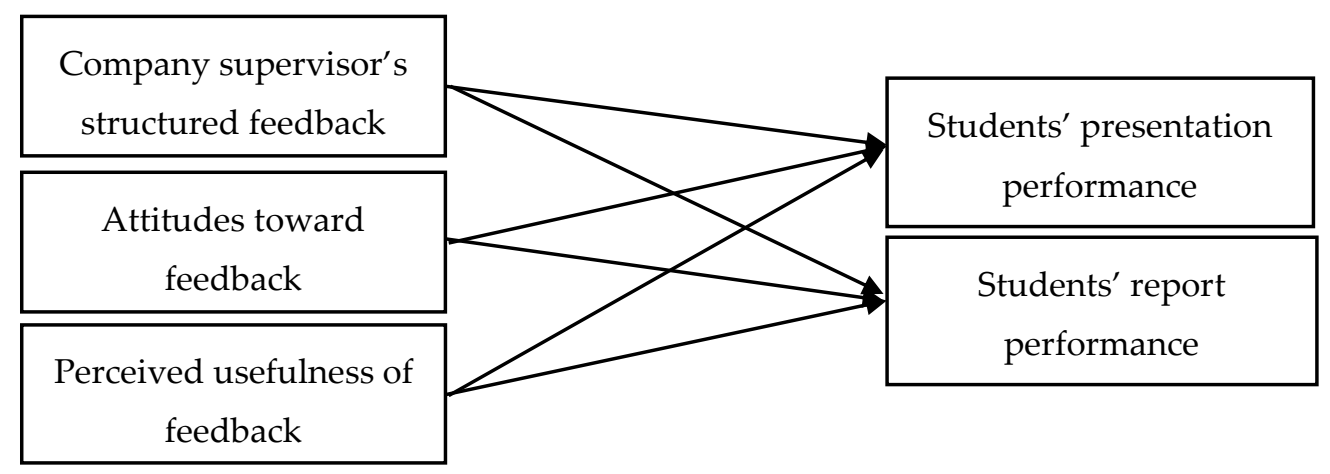

Figure 1. Conceptual model.

Hypothesis 3a: Perceived usefulness of company supervisor's feedback is positively related to students' presentation performance.

Hypothesis 3b: Perceived usefulness of company supervisor's feedback is positively related to students' report performance. 


\section{Methods}

\subsection{Procedure and Sample}

Our study adopted a quasi-experimental design with the use of a treatment group as well as a control group. The participants for this study comprised seven teams of undergraduates from the School of Business with the National University of Singapore taking the Field Service Project (FSP) module that was mandatory for final year students pursuing the Honors program of Bachelor of Business Administration. The students were expected to form teams of four to complete the FSP module in one or two semesters. The students were allowed to form their own teams or could request the School to help them form teams. In the first semester of academic year 2019-2020, there were a total of 50 teams taking the FSP module. The module coordinator reached out to these 50 teams to invite participation in our study. Seven teams of 28 students responded and consented to participate in the study. We then randomly assigned three FSP teams (12 students) to the treatment group and four FSP teams ( 16 students) to the control group. The 28 students were aged 22 to 25 years old, with 15 females and 13 males.

Students from both treatment and control groups went through their respective FSP module under the guidance of company supervisors. Each FSP was assigned at least one company supervisor throughout the entire project. The company project was typically divided into four stages: (a) scoping the requirements, (b) designing the solution, (c) implementing and evaluating the solution, and (d) presenting the report. Students were required to submit a group written report section for each stage of the project. To ensure fairness among the students, the school appointed professors to be module coordinators to screen all project proposals and approve and assign to students only those projects that were consistent in nature, scope, degree of difficulty and company expectations. In our study, we incorporated feedback on the students' project as part of formative assessment, which comprised three cycles of company supervisors' feedback and students' revisions.

In the treatment group, a feedback form was designed with the three levels of feedback (task, process, self-regulation) for company supervisors to provide written feedback to the students at the end of each of the first three stages. The fourth or final stage involved a summative grade for the presentation of the whole project. A rubric was developed based on the criteria in Table 1, to help supervisors provide structured feedback on progress at each level of students' performance-below criteria, meeting criteria, and exceeding criteria. The company supervisors were trained prior to the start of the module on the use of rubric with examples, as well as on giving verbal discursive feedback and written feedback using the structured feedback forms based on the rubrics. A questionnaire was administered at the end of the project to measure students' attitudes toward feedback and their perception on the usefulness of the feedback for improving their project.

In the control group, the company supervisors used the traditional method of providing feedback that was ad hoc in schedule and random in content exchanges with the students (with no clear distinction among the various feedback levels). The students were also invited to participate in a survey questionnaire to measure their attitudes toward feedback and the usefulness of company supervisors' feedback. 
Table 1. Criteria in rubric and feedback examples for each project stage.

\begin{tabular}{|c|c|}
\hline POBL Stages & Criteria used by Company Supervisors to Evaluate Report \\
\hline $\begin{array}{l}\text { Scoping the requirements } \\
\text { - } \quad \text { Define problem statement, customer } \\
\text { requirements, and project scope }\end{array}$ & 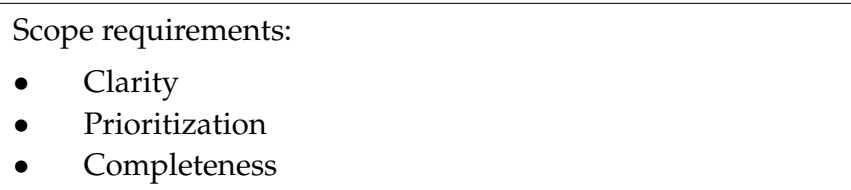 \\
\hline $\begin{array}{l}\text { Designing the Solution } \\
\text { - Design solution approach to address } \\
\text { customer requirements }\end{array}$ & 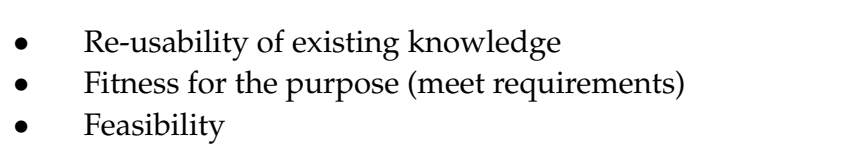 \\
\hline $\begin{array}{l}\text { Implementing and Evaluating the Solution } \\
\text { - Implement design approach and } \\
\text { evaluate solution }\end{array}$ & $\begin{array}{ll}\text { - } & \text { Robustness of proposal/ solution options } \\
\text { - } & \text { Usability } \\
\text { - } & \text { Writing and organization of report }\end{array}$ \\
\hline $\begin{array}{l}\text { - } \quad \text { Presenting the report } \\
\text { - } \quad \text { Present final report } \\
\text { All sections of the report }\end{array}$ & $\begin{array}{ll}\text { - } & \text { Robustness of proposal/ solution options } \\
\text { - } & \text { Usability } \\
\text { - } & \text { Writing and organization of report }\end{array}$ \\
\hline
\end{tabular}

\subsection{Measures and Variables}

\subsubsection{Independent Variable}

Company supervisor's structured feedback. Among the seven teams of Business School Undergraduates, three teams belong to treatment group, which received structured feedback from company supervisors, while the remaining four teams form the control group, whose company supervisors provide unstructured feedback by traditional method. Company supervisor's structured feedback is a dummy variable, which is coded for students in the treatment group, and 0 for those in the control group.

Attitudes toward feedback. At the end of project, students' attitudes toward feedback was measured by 12 items, such as "I use feedback to correct my mistakes, so that I do not repeat the same mistakes again," "Feedback enables me to make comparison and choose the best alternative solution," "I remember the answers or solutions from the feedback that my teachers provide" on a five-point Likert scale from $1=$ Strongly disagree to $5=$ Strongly agree, with Cronbach's alpha $=0.749$.

Perceived usefulness of feedback. Students were asked to respond, on a five-point Likert scale from $1=$ Strongly disagree to $5=$ Strongly agree to items "The feedback from industry supervisor was useful in revising my project," "I can understand the feedback from industry supervisor," "The industry supervisor provided feedback at task, process and self-evaluation levels (using the feedback form," "I find the industry supervisor's task level feedback the most useful for revising my project," "I find the industry supervisor's process level feedback the most useful for revising my project," "I find the industry supervisor's self-evaluation level feedback the most useful for revising my project," "I find the industry supervisor's suggestions on 'how to improve' the most useful for revising my project." Cronbach's alpha of these seven items was 0.915 .

\subsubsection{Dependent Variable}

Students' presentation performance. Students were required to present their findings at the end of the project to their company supervisors. The supervisors rated their presentation performance in various dimensions: articulation, presentation skills, knowledge of subject matters, and performance 
during question and answer. Every student was given a score in a range of $1=$ lowest to $5=$ highest by the supervisor based on the student's overall presentation performance.

Students' report performance. Each team of students was required to submit a written report as the final deliverables for the project. The report was rated by the supervisor in the following aspects: understanding of issues, conceptualization of problems, methodology and analysis, writing and organization of the report, and contribution to company. Unlike students' presentation performance graded as individual assessment, students' report performance was a group assessment where the same grade would be accorded to all four students in same team according to the team's performance.

\subsubsection{Control Variables}

Gender was controlled when we tested our model. We had a total number of 28 participants. Gender was code as 1 for the 13 male participants and 0 for the 15 female participants.

\section{Results}

Table 2 presents the mean, standard deviation, minimum, and maximum of the variables used in this study. The mean values of both presentation performance and report performance in the treatment group who received supervisor's structured feedback were higher than those in control group who did not receive structured feedback. The average presentation performance of students in treatment group was 22.50 out of 25.00 , while that in control group was 18.31 out of 25.00 . The average report performance of students in treatment group was 41.00 out of 45.00 , while that in control group was 35.00 out of 45.00 . The standard deviations of presentation performance and report performance in control group were significantly larger than those in treatment group, which showed that the variations in the project performance were larger in the control group who did not receive feedback. The results also showed that students in the treatment group and the control group reported similar attitudes toward feedback, respectively, 4.30 and 3.38. However, students with company supervisor's structured feedback in the treatment group reported lower perceived usefulness of feedback (Mean $=4.05)$ than students in control group (Mean $=4.43$ ).

Table 2. Background characteristics of the sample of participants and outcome variables.

\begin{tabular}{|c|c|c|c|c|c|c|c|c|c|}
\hline & \multirow{2}{*}{ Variables } & \multicolumn{4}{|c|}{ Treatment Group $(\mathrm{N}=12)$} & \multicolumn{4}{|c|}{ Control Group (N = 16) } \\
\hline & & Mean & SD & Minimum & Maximum & Mean & SD & Minimum & Maximum \\
\hline 1 & Students' presentation performance & 22.50 & 1.78 & 20.00 & 25.00 & 18.31 & 3.30 & 13.00 & 23.00 \\
\hline 3 & Gender & 1.75 & 0.45 & 1.00 & 2.00 & 1.38 & 0.50 & 1.00 & 2.00 \\
\hline 4 & Attitudes toward feedback & 4.30 & 0.39 & 3.58 & 4.75 & 4.38 & 0.31 & 3.83 & 5.00 \\
\hline 5 & Perceived usefulness of feedback & 4.05 & 1.02 & 2.00 & 5.00 & 4.43 & 0.50 & 3.29 & 5.00 \\
\hline
\end{tabular}

Table 3 presents correlations among the variables used in this study. The correlations below the diagonal represents associations within treatment group, while the correlations above the diagonal are associations within control group. In treatment group, the correlations between attitudes toward feedback and students' report performance were 0.922 with p-value less than 0.01 , while the correlations between usefulness of company supervisor's feedback and students' report performance were 0.672 with $\mathrm{p}$-value less than 0.05 . However, the correlations in the control group were lower than those in treatment group. The correlations between attitudes toward feedback, perceived usefulness of supervisor's feedback, and students' report performance for the treatment group were 0.922 ( $\mathrm{p}$-value $<0.01$ ) and 0.671 ( $\mathrm{p}$-value $<0.05$ ), while those for the control group were 0.574 and 0.596 , respectively, with p-value less than 0.05 . However, we failed to find such significant correlations for both control and treatment groups when it comes to students' presentation performance. The results show non-significant negative correlations of -0.193 and -0.342 between attitude toward feedback, perceived usefulness of supervisor's feedback and students' presentation performance for the treatment group. With regard to the control group, the correlations between attitude toward feedback, perceived 
usefulness of supervisor's feedback and students' presentation performance are -0.272 and 0.128 , respectively, neither of which are significant. There was a significant positive relationship between attitudes toward feedback and perceived usefulness of supervisor's feedback in the treatment group $(r=0.794, p<0.01)$, whereas there was a lower significant positive relationship in the control group $(r=0.389, p<0.10)$.

Table 3. Correlations among studying variables.

\begin{tabular}{cccccccc}
\hline & Variables & $\mathbf{1}$ & $\mathbf{2}$ & $\mathbf{3}$ & $\mathbf{4}$ & $\mathbf{5}$ & VIF \\
\hline 1 & Students' presentation performance & - & -0.348 & -0.157 & -0.272 & 0.128 & \\
2 & Students' report performance & -0.179 & - & -0.078 & $0.574^{*}$ & $0.596^{*}$ & 1.194 \\
3 & Gender & -0.056 & 0.000 & - & -0.060 & -0.188 & $1.062^{\dagger}$ \\
4 & Attitudes toward feedback & -0.193 & $0.922^{* *}$ & 0.294 & - & $0.389^{\dagger}$ & 1.878 \\
5 & Perceived usefulness of feedback & -0.342 & $0.671^{*}$ & 0.394 & $0.794^{* *}$ & - & 1.715 \\
\hline
\end{tabular}

${ }^{\dagger} \mathrm{p}<0.10 ;{ }^{*} \mathrm{p}<0.05$ (two-tailed); ${ }^{* *} \mathrm{p}<0.01$ (two-tailed), $\mathrm{N}=12$ for treatment group, $\mathrm{N}=18$ for control group. The correlation below the diagonal represent associations within treatment group, while the correlation above the diagonal are associations within control group. VIF: Variance Inflation Factor

In Table 3, the Variance Inflation Factor (VIF) values are computed to check the collinearity among the variables in our study. All of the VIF values were less than 2, so no collinearity among the variables existed in our study.

Hypothesis 1 suggested that students who received structured feedback in the treatment group have higher levels of presentation and report performances. Tables 4 and 5 present the regression results of the sample. Hypothesis 1a proposed that the structured company supervisor' feedback is positively related to students' presentation performance. As shown in Table 4, we regressed students' presentation performance on gender (control variable) in Model 1, which shows no significant relationship between gender and students' presentation performance according to the insignificant coefficient of 0.92 . In Model 2, we regressed students' presentation performance on gender and structured feedback to test hypothesis 1a. The significant coefficient of 4.46 showed that receiving supervisors' feedback causes higher presentation performance. Therefore, Hypothesis 1a was supported. Students with company supervisor's structured feedback usually reported higher presentation performance.

Table 4. Regression results on students' presentation performance.

\begin{tabular}{|c|c|c|c|c|c|c|}
\hline & \multirow{2}{*}{ Variable } & \multicolumn{5}{|c|}{ DV: Students' Presentation Performance $(\mathrm{N}=28)$} \\
\hline & & Model 1 & Model 2 & Model 3 & Model 4 & Model 5 \\
\hline 1 & Constant & $18.70^{* *}$ & 19.32 & $26.80^{* *}$ & $20.06^{* *}$ & $27.78^{* *}$ \\
\hline 2 & Gender & 0.92 & -0.73 & -0.61 & -0.69 & -0.67 \\
\hline 3 & Company supervisor's structured feedback & & $4.46^{* *}$ & $4.26^{* *}$ & $4.38^{* *}$ & $4.42^{* *}$ \\
\hline 4 & Attitudes toward feedback & & & -1.75 & & -2.48 \\
\hline \multirow[t]{4}{*}{5} & Perceived usefulness of feedback & & & & -0.18 & 0.52 \\
\hline & $R^{2}$ change & 0.02 & 0.39 & 0.42 & 0.39 & 0.42 \\
\hline & adjusted $R^{2}$ & -0.02 & 0.33 & 0.34 & 0.31 & 0.32 \\
\hline & F change & 0.49 & $7.90^{* *}$ & $5.71^{* *}$ & $5.09^{* *}$ & $4.24^{* *}$ \\
\hline
\end{tabular}

Hypothesis $2 \mathrm{a}$ and hypothesis $3 \mathrm{a}$ concern that the attitudes toward feedback and perceived usefulness of feedback variables were positively related to students' presentation. Models 3 and 4 further tested the effect of attitude and usefulness of company supervisor's structured feedback on students' presentation performance. However, the coefficients of attitudes toward feedback, -1.75 and perceived usefulness of company supervisor's feedback, -0.18 were not significant. So there is no evidence to support hypothesis $2 \mathrm{a}$ and $3 \mathrm{a}$. We therefore cannot confirm that students' presentation performance can be predicted by students' attitude toward feedback and perceived 
usefulness of supervisor's feedback. On the other hand, company supervisors' structured feedback has positive effects on students' presentation performance. As shown in the full effects of Model 5, the significant coefficient of 4.42 ( $p$-value $<0.01$ ) informs that students who receive structured feedback from their supervisors have 4.42 higher marks than students who do not receive structured feedback. Hence, we established a positive relationship between supervisors' structured feedback and students' presentation performance.

Table 5. Regression results on students' report performance.

\begin{tabular}{|c|c|c|c|c|c|c|}
\hline & \multirow{2}{*}{ Variable } & \multicolumn{5}{|c|}{ DV: Students' Report Performance (N = 28) } \\
\hline & & Model 1 & Model 2 & Model 3 & Model 4 & Model 5 \\
\hline 1 & Constant & $34.61^{* *}$ & $35.46^{* *}$ & $13.00^{*}$ & $27.53^{* *}$ & $14.33^{*}$ \\
\hline 2 & Gender & 1.93 & -0.33 & -0.70 & -0.75 & -0.79 \\
\hline 3 & Structured feedback & & $6.13^{* *}$ & $6.72^{* *}$ & $7.01^{* *}$ & $6.93^{* *}$ \\
\hline 4 & Attitudes toward feedback & & & $5.24^{* *}$ & & $4.24^{*}$ \\
\hline \multirow[t]{4}{*}{5} & Perceived usefulness of feedback & & & & $1.92^{* *}$ & 0.71 \\
\hline & $R^{2}$ change & 0.06 & 0.54 & 0.73 & 0.67 & 0.74 \\
\hline & adjusted $R^{2}$ & 0.02 & 0.51 & 0.69 & 0.62 & 0.69 \\
\hline & F change & 1.57 & $14.92^{* *}$ & $21.39 * *$ & $15.90^{* *}$ & $16.18^{* *}$ \\
\hline
\end{tabular}

Hypothesis $1 \mathrm{~b}$ suggested that the company supervisor's structured feedback is positively related to students' report performance. As shown in Table 5, we regressed students' report performance on gender in model 1, and there was not significant relationship between gender and students' report performance according to the insignificant coefficient of 1.93. In model 2, we regressed students' report performance on gender and company supervisor's structured feedback to confirm hypothesis $1 \mathrm{~b}$ that company supervisor's structured feedback can positively predict students' report performance. The significant coefficient of 6.13 (p-value $<0.01$ ) in model 2 shows that students with company supervisor's structured feedback get better report performance, thereby supporting hypothesis $1 \mathrm{~b}$.

Models 3 and 4 further tested the effect of attitudes toward feedback and perceived usefulness of supervisors' feedback on students' report performance. The result show that students with higher level of attitudes toward feedback are more likely to have higher level of report performance, with the coefficient of 5.24, p-value less than 0.01 , hence supporting hypothesis $2 \mathrm{~b}$ that students' attitudes toward feedback is positively related to their report performance. Similarly, hypothesis $3 \mathrm{~b}$ suggested that students' perceived usefulness of company supervisor's feedback is positively related to their report performance. The coefficient of 1.92 indicated the significant positive relationship between perceived usefulness of feedback and report performance also exists, with p-value less than 0.01 . The positive influence of usefulness of company supervisor's feedback was slightly lower than that of attitudes toward feedback. The positive coefficients of structured feedback are still statistically significant in Models 3 and 4. Specifically, the coefficients of structured feedback are 6.72 in Model 3 with variable of attitudes toward feedback included and 7.01 in Model 4 with perceived usefulness of feedback included. The significant coefficient of 6.93 ( $p$-value $<0.01$ ) in the full effects of Model 5 shows that students who receive structured feedback from their supervisors have 6.93 higher marks on their report performance than students who do not receive structured feedback. Hence, we established a positive relationship between supervisors' structured feedback and students' report performance.

To address our research questions, we use multivariate analysis of variance (MANOVA) (Table 6) to demonstrate there was a significant effect of structured feedback on the combined dependent variables (students' presentation performance and report performance), $\mathrm{F}(4,23)=32.52, \mathrm{p}<0.01$, partial $\eta^{2}=0.72$ 
Table 6. Multivariate and univariate analyses of variance $F$ ratios for structured feedback $x$ (students' performances, attitudes, and perceptions of usefulness).

\begin{tabular}{ccccccc}
\hline Variables & \multicolumn{3}{c}{ MANOVA } & \multicolumn{3}{c}{ ANOVA } \\
\cline { 2 - 7 } & $\boldsymbol{F ~ ( 4 , ~ 2 3 )}$ & $p$ & $\eta^{\mathbf{2}}$ & $\boldsymbol{F ~ ( 1 , ~ 2 6 ) ~}$ & $p$ & $\eta^{\mathbf{2}}$ \\
\hline Structured feedback & $32.52^{* *}$ & 0.000 & 0.72 & & & \\
Students' presentation performance & & & & $15.75^{* *}$ & 0.001 & 0.38 \\
Students' report performance & & & & $30.86^{* *}$ & 0.000 & 0.54 \\
Attitudes toward feedback & & & & 0.44 & 0.515 & 0.02 \\
Perceived usefulness of feedback & & & & 1.71 & 0.203 & 0.06 \\
\hline
\end{tabular}

One-way analysis of variance (ANOVA) was used to determine whether there was any significant difference between the responses in the treatment group who received company supervisor's structured feedback and those in the control group who did not receive such feedback. Analysis of dependent variables individually reveals there were non-significant effects of structured feedback on the attitudes toward feedback and perceived usefulness of feedback variables. However, presentation performance and report performance were statistically significant, respectively, $\mathrm{F}(1,26)=15.75, \mathrm{p}<0.01)$, partial $\eta^{2}=0.38, F(1,26)=30.86, p<0.01$, partial $\eta^{2}=0.54$. These findings indicated that students who received structured feedback from company supervisors demonstrated significantly higher positive presentation and report performance than those who did not.

\section{Discussion}

Our study has several findings and implications. First, students in the treatment group who received company supervisor's structured feedback exhibited higher levels of project performance, including presentation and report, than those in control group, who did not receive structured feedback. These findings are supportive of the general argument that feedback is regarded as one of the most important ways to increase student learning [22]. Feedback plays an important role in determining students' performance in the context of PBL. When students experience PBL with guidance from the company's supervisor in a specific company for a certain project, feedback is very important for their knowledge acquisition and skill improvement. In addition, our study shows similar positive effects of feedback received after task engagement on the learning outcomes of students. After the supervisors have provided students with three-level feedback (including task, process, and self-regulation) at three milestones stages, supervisor's feedback can be helpful for students to reduce the discrepancy between their current performance and a goal [29]. Sometimes, students in the PBL setting are unable to confidently and objectively evaluate their own performance. During these moments, supervisor feedback can provide important information to the students about the extent their learning performance has improved [39]. So, students in treatment group who received supervisor's structured feedback are more likely to perform better than those in control group who did not receive such feedback. This is because students with structured feedback can focus more attention on what to improve. Therefore, in the context of higher education, a company supervisor's structured feedback to students in PBL on their performance is an effective and efficient teaching strategy for company-based project learning. As a new teaching methodology, structured feedback in PBL is not only a practical way to cultivate an open mind among students and guide them towards better performance, but also essential for education for sustainable development.

Second, our findings show that students' attitudes toward company supervisor's feedback helped them to achieve higher report performance. The positive impact of students' attitudes toward feedback on presentation performance, however, is not evident. This finding is in line with previous research that a positive attitude toward company supervisor's feedback is more likely to lead to learning [40] rather than actual performance. Learners' autonomy and initiative are important in PBL. Student should be active receiver in feedback process; that means if students do not act upon the feedback or 
digest it, even though the supervisor's feedback is helpful or constructive, the feedback is still useless to the students [41]. Students should first understand and appreciate the role of feedback in improving work before the feedback functions [34]. Positive attitude will facilitate the adoption of supervisor's structured feedback and students can acquire more knowledge and skills. Developing more positive attitude is essential and crucial in PBL in higher education.

Third, our results establish a significantly positive relationship between perceived usefulness of company supervisor's feedback and report performance. This is corroborated by earlier studies that argued the significance of students' higher usefulness perception [42]. Our study extends the literature by demonstrating how students working on company projects outside traditional classroom learning perceive their company supervisor's structured feedback can affect the effectiveness of the PBL method. Specifically, feedback is helpful for students to identify and correct misunderstanding and errors, develop more practical and powerful strategies, and improve their self-regulation $[43,44]$. Thus, students' perceived usefulness of the feedback is necessary for improving their project performance. They will take more initiative to understand and digest the contents of supervisor's structured feedback. However, there is not enough evidence to support that students' perceived usefulness of company supervisor's feedback is positively related to their presentation performance. Neither positive attitudes toward feedback nor high level of perceived usefulness of company supervisor's feedback can contribute to better presentation performance. The contents of company supervisor's feedback may account for this result. The focus of feedback concerns the students' performance and understanding of the project's subject, research methodology, or analysis process, which are beneficial for students to understand main issues of the company for meaningful contribution to the company projects. The evaluation items of report performance are more about the understanding or analysis of the project while the items of presentation are more about performance such as articulation or presentation skills that cannot be gained from this kind of feedback. Another possible reason is that supervisors provide feedback throughout the whole process of organizing report, whereas students always prepare for the presentation at the end of the project [45]. It is therefore plausible that students do not gain enough feedback from their supervisors, who may consider as more crucial the completeness and accuracy of the report content. Future studies can stimulate supervisors to provide more feedback on aspects related to presentation. In addition, given the small sample size of this study, certain effects of the underlying factors may not be observable. Future research can repeat this experiment by including more students.

From a theoretical perspective, we have integrated the concept of multi-level structured feedback with PBL learning approach. Offering structured feedback is essential for students' improvement. In practice, our study has provided insight on ways to enhance the effectiveness of future project-based study in higher education. The findings also have important implications for learners who should improve their attitudes toward feedback and consider how their perceived usefulness to supervisors' feedback can support their knowledge augmentation and skill development.

Author Contributions: Conceptualization, S.C.; methodology, S.C.; software, S.C.; validation, S.C. and S.L.; formal analysis, S.C. and S.L.; investigation, S.C. and S.L.; resources, S.C.; data curation, S.C. and S.L.; writing-original draft preparation, S.L.; writing—review and editing, S.L. and S.C.; visualization S.L.; supervision, S.C.; project administration, S.C.; funding acquisition S.C. All authors have read and agreed to the published version of the manuscript.

Funding: This research was funded by the Ministry of Education of Singapore Teaching Research Fund (MOE TRF), grant number R-317-000-136-116. The APC was funded by the MOE TRF, grant number R-317-000-136-116.

Acknowledgments: We acknowledge Mark Gan, Bimlesh Wadhwa, Su Kee Tan, Can Chen, and Wisam M.R. Zaqoot for their support of this study.

Conflicts of Interest: The authors declare no conflict of interest. The funders had no role in the design of the study in the collection, analyses, or interpretation of data, in the writing of the manuscript, and in the decision to publish the results. 


\section{References}

1. Hannum, P. Food security, economy to be hit by climate change, leaked IPCC draft report shows. Syd. Morning Her. 2014, 19, 2014.

2. Nevin, E. Education and sustainable development. Policy Pract. -A Dev. Educ. Rev. 2008, 6, 49-62.

3. Brundtland, G. Our Common Future: The World Commission on Environment and Development; Oxford University Press: Oxford, UK, 1978.

4. Svanström, M.; Lozano-García, F.J.; Rowe, D. Learning outcomes for sustainable development in higher education. Int. J. Sustain. High. Educ. 2008, 9, 339-351. [CrossRef]

5. Cheah, S.; Li, S.; Ho, Y.P. Mutual Support, Role Breadth Self-Efficacy, and Sustainable Job Performance of Workers in Young Firms. Sustainability 2019, 11, 3333. [CrossRef]

6. Urquidi-Martín Tamarit-Aznar, C.; Sánchez-García, J. Determinants of the Effectiveness of Using Renewable Resource Management-Based Simulations in the Development of Critical Thinking: An Application of the Experiential Learning Theory. Sustainability 2019, 11, 5469. [CrossRef]

7. Kolb, D.A. Experiential learning: Experience as the Source of Learning and Development, 2nd ed.; Pearson Education Ltd.: Upper Saddle River, NJ, USA, 2015.

8. Cazorla-Montero, R.C.; Paste, D.L. Sustainable development planning: Master's based on a project-based learning approach. Sustainability 2019, 11, 6384. [CrossRef]

9. Liu, H.; Wang, Q.; Su, Y.; Zhou, L. Effects of project-based learning on teachers' information teaching sustainability and ability. Sustainability 2019, 11, 5795. [CrossRef]

10. Cheah, S.; Bellavitis, C.; Muscio, A. The impact of technology complexity on the financial performance of R\&D projects: Evidence from Singapore. J. Technol. Transf. 2020, 13, 1-28.

11. Chang, C.; Kuo, C.; Chang, Y. An assessment tool predicts learning effectiveness for project-based learning in enhancing education of sustainability. Sustainability 2018, 10, 3595. [CrossRef]

12. Renganathan, S.; Ambri Bin Abdul Karim, Z.; Su, L.C. Students' perception of industrial internship programme. Educ. + Train. 2012, 54, 180-191. [CrossRef]

13. McKenzie, S.; Burgess, A.; Mellis, C. Interns reflect: The effect of formative assessment with feedback during pre-internship. Adv. Med. Educ. Pract. 2017, 8, 51. [CrossRef] [PubMed]

14. Ibrahim, J.; MacPhail, A.; Chadwick, L.; Jeffcott, S. Interns' perceptions of performance feedback. Med. Educ. 2014, 48, 417-429. [CrossRef] [PubMed]

15. Ramani, S.; Krackov, S.K. Twelve tips for giving feedback effectively in the clinical environment. Med. Teach. 2012, 34, 787-791. [CrossRef] [PubMed]

16. Gigante, J.; Dell, M.; Sharkey, A. Getting beyond "good job": How to give effective feedback. Pediatrics 2011, 127, 205-207. [CrossRef] [PubMed]

17. Le, P.T.A.; Vásquez, C. Feedback in teacher education: Mentor discourse and intern perceptions. Teach. Dev. 2011, 15, 453-470. [CrossRef]

18. Motley, V.; Reese, M.K.; Campos, P. Evaluating Corrective Feedback Self-Efficacy Changes Among Counselor Educators and Site Supervisors. Couns. Educ. Superv. 2014, 53, 34-46. [CrossRef]

19. Al-Hattami, A.A. The Perception of Students and Faculty Staff on the Role of Constructive Feedback. Int. J. Instr. 2019, 12, 885-894. [CrossRef]

20. Henderson, M.; Phillips, M. Video-based feedback on student assessment: Scarily personal. Australas. J. Educ. Technol. 2015, 31, 51-66. [CrossRef]

21. Carver, M. Helping students to explain what they want from feedback: Findings from a large-scale survey. Pract. Res. High. Educ. 2016, 10, 39-52.

22. Hattie, J.; Timperley, H. The Power of Feedback. Rev. Educ. Res. 2007, 77, 81-112. [CrossRef]

23. Narciss, S. Designing and evaluating tutoring feedback strategies for digital learning environments on the basis of the interactive tutoring feedback model. Digit. Educ. Rev. 2013, 23, 7-26.

24. Hutchison, S.; Garstka, M. Sources of perceived organizational support: Goal setting and feedback. J. Appl. Soc. Psychol. 1996, 26, 1351-1366. [CrossRef]

25. Fyfe, E.R. Providing feedback on computer-based algebra homework in middle-school classrooms. Comput. Hum. Behav. 2016, 63, 568-574. [CrossRef]

26. Fyfe, E.R.; Rittle-Johnson, B.; Decaro, M.S. The effects of feedback during exploratory mathematics problem solving: Prior knowledge matters. J. Educ. Psychol. 2012, 104, 1094-1108. [CrossRef] 
27. Earley, P.C. Computer-generated performance feedback in the magazine subscription industry. Organ. Behav. Hum. Decis. Process. 1988, 41, 50-64. [CrossRef]

28. Wang, Z.; Gong, S.; Xu, S.; Hu, X. Elaborated feedback and learning: Examining cognitive and motivational influences. Comput. Educ. 2019, 136, 130-140. [CrossRef]

29. Shute, V.J. Focus on formative feedback. Rev. Educ. Res. 2008, 78, 153-189. [CrossRef]

30. Sweller, J. Cognitive load during problem solving: Effects on learning. Cogn. Sci. 1988, 12, $257-285$. [CrossRef]

31. Paas, F.; Renkl, A.; Sweller, A. Cognitive load theory and instructional design: Recent developments. Educ. Psychol. 2008, 38, 1-4. [CrossRef]

32. Kulhavy, R.W. Feedback in written instruction. Rev. Educ. Res. 1977, 47, 211-232. [CrossRef]

33. Butler, D.L.; Winne, P.H. Feedback and self-regulated learning: A theoretical synthesis. Rev. Educ. Res. 1995, 65, 245-274. [CrossRef]

34. Carless, D.; Boud, D. The development of student feedback literacy: Enabling uptake of feedback. Assess. Eval. High. Educ. 2018, 43, 1315-1325. [CrossRef]

35. Sutton, P. Conceptualizing feedback literacy: Knowing, Being and Acting. Innov. Educ. Teach. Int. 2012, 49, 31-40. [CrossRef]

36. Strobl, C. Attitudes towards online feedback on writing: Why students mistrust the learning potential of models. ReCALL 2015, 27, 340-357. [CrossRef]

37. Gibbs, G.; Simpson, C. Measuring the response of students to assessment: The assessment experience questionnaire. Improv. Stud. Learn. Symp. 2013, 11, 1-12.

38. Harks, B.; Rakoczy, K.; Hattie, J.; Besser, M.; Klieme, E. The effects of feedback on achievement, interest and self-evaluation: The role of feedback's perceived usefulness. Educ. Psychol. 2014, 34, 269-290. [CrossRef]

39. Idris, A.Y. Investigating the Effects of the Supervisor's Feedback on International Masters Students' Dissertation Writing Outcomes in the UK. Ph.D. Thesis, University of Warwick, Coventry, UK, 2011.

40. Faqeih, H.I. Learners' attitudes towards corrective feedback. Procedia-Soc. Behav. Sci. 2015, 192, $664-671$. [CrossRef]

41. De Kleijn, R.A.; Mainhard, M.T.; Meijer, P.C.; Brekelmans, M.; Pilot, A. Master's thesis projects: Student perceptions of supervisor feedback. Assess. Eval. High. Educ. 2013, 38, 1012-1026. [CrossRef]

42. Weaver, M.R. Do students value feedback? Student perceptions of tutors' written responses. Assess. Eval. High. Educ. 2006, 31, 379-394. [CrossRef]

43. Van der Kleij, F.M.; Feskens, R.C.; Eggen, T.J. Effects of feedback in a computer-based learning environment on students' learning outcomes: A meta-analysis. Rev. Educ. Res. 2015, 85, 475-511. [CrossRef]

44. Cheah, S.; Yoneyama, S.; Ho, Y.P. Performance management of public-private collaboration in innovation. Creat. Innov. Manag. 2019, 28, 563-574. [CrossRef]

45. Cheah, S.; Ho, Y.P. Effective industrial policy implementation for open innovation: The role of government resources and capabilities. Technol. Forecast. Soc. Chang. 2020, 151, 119845. [CrossRef]

(C) 2020 by the authors. Licensee MDPI, Basel, Switzerland. This article is an open access article distributed under the terms and conditions of the Creative Commons Attribution (CC BY) license (http://creativecommons.org/licenses/by/4.0/). 